\title{
Identification of peripheral arterial disease in diabetic patients and its association with quality of life, physical activity and body composition
}

\author{
Identificação de doença arterial obstrutiva periférica e sua associação com a qualidade \\ de vida, a atividade física e a composição corporal em pacientes diabéticos
}

Ana Tereza do Nascimento Sales', Guilherme Augusto de Freitas Fregonezi 1,2, Ana Gabriela Câmara Batista Silva', Cibele Teresinha Dias Ribeiro', Mario Emílio Teixeira Dourado-Junior ${ }^{3}$, André Gustavo Pires Sousa ${ }^{4}$,

Fernando Augusto Lavezzo Dias ${ }^{1,5}$

\begin{abstract}
Background: Diabetes mellitus (DM) is a risk factor for peripheral arterial disease (PAD). Neither the prevalence of PAD in type 2 (T2) DM nor its detrimental effects on quality of life (QoL) or physical activity (PA) have been well described in the Brazilian population. Objectives: To evaluate the prevalence of newly diagnosed PAD and its associations with QoL, PA and body composition in a sample of T2DM patients from a University Hospital. Methods: Seventy-three (73) T2DM patients without previous diagnoses of major complications related to T2DM were enrolled. PAD was assessed using the ankle-brachial index (ABI); QoL was measured using a translated and validated SF-36 questionnaire; PA was measured using a modified Baecke questionnaire; and body composition was measured by segmental multi-frequency bioelectrical impedance. Results: PAD prevalence was $13.7 \%$, predominantly of mild severity ( $A B$ B between 0.8-0.9). The $A B \mid$ results correlated with age $(\rho=-0.26, P=0.03)$, DM duration $(\rho=-0.28, P=0.02)$ and systolic and diastolic blood pressure $(\rho=-0.33, P=0.007$ and $\rho=-0.28, P=0.02$; respectively). Scores for the SF-36 physical component summary (PCS) were below the normal range, but no negative impact from PAD was identified by the PCS scores (normal-ABI $42.9 \pm 11.2$ vs. PAD-ABI 38.12 \pm 11.07 ) or the Baecke PA results. Body composition analysis detected excessive body fat, especially in women, but there was no difference between groups. Conclusions: The prevalence of previously undiagnosed PAD in this population of T2DM patients was $13.7 \%$, predominantly mild and asymptomatic forms, and was not yet associated with worsened QoL, PA levels or body composition variables.
\end{abstract}

Keywords: Peripheral Arterial Disease; Diabetes Mellitus; diabetes complications; quality of life; body composition.

\begin{abstract}
Resumo
Contexto: $O$ Diabetes Mellitus (DM) é fator de risco para a doença arterial obstrutiva periférica (DAOP). A prevalência de DAOP no DM tipo 2 (T2) e o prejuízo adicional causado por esta na qualidade de vida (QoL) e na atividade física (AF) não são bem descritos na população brasileira. Objetivos: Avaliar a prevalência e a associação da DAOP recémdiagnosticada com a QoL, a AF e a composição corporal em pacientes T2DM provenientes de um hospital universitário. Métodos: Setenta e três pacientes T2DM, sem complicações maiores relacionadas ao T2DM, foram incluídos. A DAOP foi avaliada pelo índice tornozelo-braquial (ITB); a QoL, pelo questionário traduzido e validado SF-36, e a AF, pelo questionário modificado de Baecke. A composição corporal foi avaliada pela impedância bioelétrica segmentar multifrequencial. Resultados: A prevalência de DAOP foi 13,7\%, predominantemente de severidade leve (ITB entre 0,8-0,9). O ITB correlacionou-se com a idade $(\rho=-0,26 ; P=0,03)$, a duração do $D M(\rho=-0,28 ; P=0,02)$ e a pressão arterial sistólica $e$ diastólica ( $\rho=-0,33 ; P=0,007$ e $\rho=-0,28 ; P=0,02$; respectivamente). O sumário de saúde física (PCS) do questionário SF-36 estava abaixo da variação normal; contudo, nenhum impacto negativo da DAOP foi identificado no PCS (ABI normal $=42,9 \pm 11,2$ vs. ABI-DAOP = 38,12 $\pm 11,07$ ) ou no nível de AF. A análise da composição corporal demonstrou gordura corporal excessiva, especialmente em mulheres; contudo, sem diferenças entre grupos. Conclusão: A prevalência de DAOP sem diagnóstico prévio nesta amostra de pacientes T2DM foi de 13,7\%, predominantemente assintomática e leve, e ainda não associada com piores índices de QoL, nível de AF e composição corporal.
\end{abstract}

Palavras-chave: Doença arterial periférica; Diabetes Melito; complicações do diabetes; qualidade de vida; composição corporal.

\footnotetext{
'Universidade Federal do Rio Grande do Norte - UFRN, Graduate Program in Physical Therapy, Natal, RN, Brazil.

${ }^{2}$ Universidade Federal do Rio Grande do Norte - UFRN, Department of Physical Therapy, Natal, RN, Brazil.

3Universidade Federal do Rio Grande do Norte - UFRN, Department of Integrated Medicine, Natal, RN, Brazil.

${ }^{4}$ Universidade Federal do Rio Grande do Norte - UFRN, Department of Clinical Medicine, Natal, RN, Brazil.

SUniversidade Federal do Paraná - UFPR, Department of Physiology, Curitiba, PR, Brazil.

Financial support: This study received financial support from the grant PPSUS III-DECIT/SCTIE/MS, through the National Research Council (CNPq), FAPERN and SESAP/RN.

Conflicts of interest: No conflicts of interest declared concerning the publication of this article.

Submitted: May 20, 2014. Accepted: September 16, 2014.
}

The study was carried out at University Hospital Onofre Lopes - Federal University of Rio Grande do Norte, Section of Endocrinology and Section of Physical Therapy, Outpatient clinic. 


\section{INTRODUCTION}

Peripheral arterial disease (PAD) predominantly affects the elderly and prevalence increases with age in both genders. ${ }^{1,2}$ Its prevalence in the general population varies from 4 to $10 \%$ and can exceed $20 \%$ in patients over the age of $70 .^{3}$ Despite this, there is a low prevalence of symptomatic patients with intermittent claudication. ${ }^{1,2}$ Few epidemiologic studies of PAD have been conducted in Brazil. One multicenter study ${ }^{4}$ described a PAD prevalence of $10.5 \%$ in the general population and found that only $9 \%$ of patients reported claudication.

There is a strong association between PAD and Diabetes Mellitus (DM), ${ }^{5,6}$ but PAD prevalence rates have not been determined in diabetes patients with the same degree of precision as in the general population. Peripheral arterial disease is a major risk factor for lower-extremity amputation ${ }^{7-10}$ and patients with PAD and diabetes are at greater risk of amputations than PAD patients free from diabetes. ${ }^{11}$ Patients with DM have a high risk of developing PAD, and early identification of this disease is potentially a clinical strategy for reducing morbidity and mortality in this population. ${ }^{6,11}$

Impacts on quality of life (QoL) have been described in both diseases, diabetes and PAD. ${ }^{12-15}$ In PAD, symptom severity is associated with worse quality of life indices. ${ }^{12}$ Furthermore, PAD progression may correlate with reduced physical function.

In view of the fact that there is a paucity of epidemiological data on the prevalence of PAD in the Brazilian population, particularly among patients with diabetes, and also that the impact PAD has on quality of life and physical activity in patients with diabetes without prior diagnosis of PAD is not yet well established, we conducted a study with the objective of determining the prevalence of PAD and assessing its impact on quality of life, physical activity levels and body composition in a sample of diabetic patients treated by the public health system at a University Hospital in Brazil.

\section{METHODS}

\section{Subjects}

The study enrolled volunteers with diagnoses of type 2 diabetes mellitus (T2DM) who were being monitored and given treatment for DM at the Endocrinology outpatients clinic at Onofre Lopes University Hospital (HUOL-UFRN) in Natal, Brazil. All patients were treated by the Brazilian public health system (SUS - Sistema Único de Saúde).
Sample size was calculated using methodology described by Lwanga and Lemeshow, ${ }^{16}$ based on data that estimated PAD prevalence in DM patients at $20 \%$ to $29 \%$ (identified using the same method employed in the present study, i.e., ABI), ${ }^{10}$ for an absolute precision of 10 and a significance level of $5 \%$, resulting in a sample size of 72 subjects.

For inclusion in the study, subjects had to have been diagnosed with T2DM and have no prior diagnoses of: PAD, advanced heart disease such as chronic heart failure, diabetic neuropathy, neuromuscular disease or rheumatic or metabolic diseases (except DM), which could influence the exercise capacity assessments administered during clinical assessment. Patients with previous amputations or who had received revascularization of coronary or peripheral arterial beds were excluded from the study.

Patients were invited to participate on days on which they were attending the outpatients clinic. After a brief interview and review of clinical records, volunteers were enrolled on the study if they met the inclusion criteria and gave their written consent as required by the Research Ethics Committee at the HUOL-UFRN (approval number 421/10) and in accordance with Brazilian legislation (res. 196/96) and the Helsinki Declaration.

\section{Anthropometric measurements}

Body weight and height were measured using a mechanical scale with a stadiometer attached (Welmy, Brazil). Body mass index (BMI) was classified according to World Health Organization ${ }^{17}$ recommendations. Waist and hip circumference and the waist-to-hip ratio (WHR) were measured using methodology that had been described elsewhere. ${ }^{18}$

\section{Body composition}

Body composition was assessed using the Direct Segmental Multi-frequency Bioelectrical Impedance method, as described elsewhere. ${ }^{19,20}$ An Inbody R20 portable body composition analyzer (Biospace, South Korea) with eight electrodes, two for each foot and two for each hand, was used to determine segmental electrical impedance using a $250 \mu \mathrm{A}$ current at frequencies of $20 \mathrm{kHz}$ and $100 \mathrm{kHz}$. Total body water (TBW) was calculated using five segmental impedance measurements. Muscle mass was estimated from TBW assuming a hydration of fat-free mass (FFM) rate of $73.2 \%$. Fat mass (FM) was calculated by subtracting FFM from body weight. Body fat mass was also expressed as body fat percentage (BFP). Basal metabolic rate (BMR) 
was calculated using a regression equation based on FFM. Body Fat Mass Index (BFMI) was calculated as the ratio of body FM (Kg) by Height (m) squared $\left(\mathrm{Kg} / \mathrm{m}^{2}\right)$.

\section{Ankle-brachial index (ABI)}

The ankle-brachial index (ABI) was measured by a single trained examiner using a sphygmomanometer (Durashock DS44, WelchAllyn/Tycos ${ }^{\circledR}$ ) with cuffs suitable for the circumferences of the patients' limbs and a $10 \mathrm{MHz}$ portable Doppler machine (DV-10, Microem).

Ankle-brachial index was determined for each leg by taking the ratio between the highest systolic blood pressure measured at the ankle (posterior tibial and dorsalis pedis arteries) and the highest systolic blood pressure measured in the arms (brachial artery)., 3,21 The test methodology and ABI classification were based on American College of Cardiology/American Heart Association (ACC/AHA) recommendations..$^{21,22}$ Ankle-brachial index values from 0.91 to 1.39 were considered normal. Values equal to or less than 0.90 were considered compatible with PAD and values equal to or greater than 1.40 were considered abnormal but inconclusive for PAD, designating non-compressible arteries that require additional assessments by other techniques for identification or exclusion of PAD. ${ }^{3,21}$ Peripheral arterial disease was classified as mild to moderate where ABI values fell between 0.41 and 0.9 and severe for values lower than 0.4. ${ }^{21,22}$

\section{Quality of life}

Quality of life was assessed using the SF-36 health-related quality of life questionnaire (Medical Outcomes Short Form 36), as translated into Portuguese and adapted for the Brazilian population..$^{23}$ Although the questionnaire is self-administrable, it was administered during interviews.

To aid with analysis and interpretation, scores were also standardized using standard deviations from the general population (Z-scores, mean of 50 and standard deviation of 10). Standardized values were calculated using data from a 1998 national survey of the US population (SF-36v2 ${ }^{\text {TM }}$ Health Survey 1998 U.S. general population norms) and from algorithms based on scoring standardized to eight domains of the questionnaire, available at www. sf-36.org (Norm base score calculator, accessed on January, 2012). The results are shown in the form of two summaries, the Physical Component Summary (PCS) and Mental Component Summary (MCS).

\section{Physical activity levels}

Physical activity levels were assessed using the Modified Baecke Questionnaire, as translated into Portuguese and validated. ${ }^{24}$ This consists of a recall of energy expenditure in the last twelve months. Although this questionnaire is also selfadministrable, it too was administered during interviews. For the Baecke questionnaire, total scores (TS) were used for statistical analysis.

\section{Statistical analysis}

Results are expressed as means and standard deviations. Patients were divided into two groups on the basis of $\mathrm{ABI}$ results: a normal $\mathrm{ABI}$ group, for those with normal $\mathrm{ABI}$ values and a PAD ABI group, for patients with $\mathrm{ABI}$ results $\leq 0.90$. Volunteers whose ABI was $>1.40$ were excluded from the groups used to compare variables and from the correlation coefficient calculations, because these ABI values are inconclusive for PAD diagnosis., ${ }^{3,21}$ Therefore, as described in greater detail in the results section, 66 patients from the total of 73 assessed were classed as having normal ABI $(\mathrm{n}=56)$ or PAD ABI $(n=10)$, for the purposes of comparing variables.

Normality of data was verified using the Kolmogorov-Smirnov test. The Mann-Whitney test was used to compare variables between groups. Correlations were identified by calculating Spearman correlation coefficients $(\rho)$. Where correlation tests involved ABI results, the lowest numerical ABI value for each patient was used. The Chi-Square test was used to test associations between frequencies of smoking, high blood pressure and insulin use and membership of each of the two groups of volunteers. Values of $P<0.05$ were adopted as the criterion for statistical significance. The software packages used for statistical calculations were Graphpad Prism 4.0 for Windows and the Statistical Package for the Social Sciences-SPSS 17.0.

\section{RESULTS}

A total of 73 patients, 51 women $(69.8 \%)$ and 22 men (30.2\%), met all inclusion criteria and were therefore included in the study. Data describing the general characteristics of the population and the groups of patients with normal ABI and PAD ABI are shown in Table 1. No statistical differences were detected when the variables were compared between groups, with the exception of a trend to exhibit higher systolic blood pressure in the PAD ABI group $(P=0.0502)$. 
The results showed that $23.2 \%(17 / 73)$ of the patients had abnormal ABI values and that the prevalence of patients with $\mathrm{ABI}$ compatible with a diagnosis of PAD was $13.7 \%(10 / 73)$. Seven patients had ABI values $>1.40(9.6 \%)$. Therefore, from a total of 73 patients assessed, 66 were classified as having normal $\mathrm{ABI}(\mathrm{n}=56)$ or PAD ABI $(\mathrm{n}=10)$ for the purposes of comparing variables.

The means and standard deviations for $\mathrm{ABI}$ values of the normal $\mathrm{ABI}$ group and the PAD ABI group were $1.10 \pm 0.08$ and $0.93 \pm 0.17$ for the right side and $1.08 \pm 0.08$ and $0.83 \pm 0.13$ for the left side respectively. The mean and standard deviation for the lowest $\mathrm{ABI}$ value of individuals with $\mathrm{PAD}$ were $0.83 \pm 0.12$.

The means and standard deviations for the quality of life questionnaire physical health summary (PCS) and mental health summary(MCS) and for the modified Baecke questionnaire total scores (TS) are shown in Table 2. There were no statistical differences between groups when these variables were compared. However, the population of patients with both diabetes and PAD had physical health summary scores $(\mathrm{PCS}=38.1 \pm 11.1)$ one standard deviation below the expected normal values (mean below 50), demonstrating reduced physical health compared to the normal population.
Anthropometric data on waist and hip circumferences and WHR and body composition data by sex are shown in Table 3 . The results are broken down by sex, because cut off values for the variables tested are different for men and women. Two patients' bioelectrical impedance data (1 man in the PAD group and one woman with $\mathrm{ABI}>1.4$ ) could not be acquired because of technical problems at the exact moment of clinical evaluation.

Figure 1 illustrates the results for the Spearman coefficients for correlations between $\mathrm{ABI}$ and the following variables: age, diabetes duration (time in years since the date of diagnosis, as reported by the patient), SBP and DBP. Correlations between these variables and $\mathrm{ABI}$ were significant and the correlation coefficients were negative in all cases. None of the other variables tested exhibited significant correlations (ABI vs. PHS, $P=0.30$ and $\rho=-0.13$; ABI vs. MHS, $P=0.47, \rho=-0.09$; ABI vs. Baecke TS, $P=0.72$ and $\rho=0.04$; ABI vs. BMI, $P=0.50$ and $\rho=0.08$ ).

Table 4 lists the Spearman coefficients for correlations between $\mathrm{ABI}$ and the anthropometric variables and body composition. There was a trend towards lower fat free mass $(P=0.05)$ and skeletal muscle mass $(P=0.06)$ among women with lower $\mathrm{ABI}$ results.

Table 1. Clinical characteristics of the study population and comparison of patients with normal $A B I$ and patients with $A B I$ compatible with PAD.

\begin{tabular}{|c|c|c|c|c|}
\hline & $\begin{array}{c}\text { All } \\
(\mathrm{N}=73)\end{array}$ & $\begin{array}{c}\text { Normal ABI } \\
(\mathrm{N}=56)\end{array}$ & $\begin{array}{c}\text { PAD ABI } \\
(\mathrm{N}=10)\end{array}$ & $P$ value \\
\hline Age (years) & $55.7 \pm 11.2$ & $54.2 \pm 11.0$ & $59.0 \pm 11.6$ & 0.09 \\
\hline Weight (Kg) & $69.6 \pm 13.8$ & $69.7 \pm 14.6$ & $70.9 \pm 13.5$ & 0.70 \\
\hline Height (cm) & $155.6 \pm 8.1$ & $155.6 \pm 8.35$ & $154.4 \pm 6.5$ & 0.98 \\
\hline $\mathrm{BMI}\left(\mathrm{Kg} / \mathrm{m}^{2}\right)$ & $28.6 \pm 5.4$ & $28.8 \pm 5.8$ & $28.8 \pm 5.1$ & 0.86 \\
\hline $\mathrm{SBP}(\mathrm{mmHg})$ & $133.9 \pm 16.9$ & $131.6 \pm 16.4$ & $142.0 \pm 16.9$ & 0.05 \\
\hline $\mathrm{DBP}(\mathrm{mmHg})$ & $81.8 \pm 9.2$ & $81.1 \pm 8.9$ & $86.0 \pm 11.7$ & 0.23 \\
\hline HR (bpm) & $75.1 \pm 10.8$ & $75.2 \pm 10.4$ & $74.8 \pm 11.6$ & 0.96 \\
\hline DM duration (years) & $8.0 \pm 7.4$ & $7.5 \pm 6.6$ & $8.3 \pm 8.1$ & 0.81 \\
\hline $\mathrm{HBP}(\%)$ & 60.3 & 59.0 & 50.0 & 0.60 \\
\hline Smoking (\%) & 24.6 & 26.7 & 10.0 & 0.25 \\
\hline Insulin (\%) & 50.7 & 50.0 & 40.0 & 0.56 \\
\hline
\end{tabular}

BMI Body mass index; SBP Systolic blood pressure; DBP Diastolic blood pressure; HR Heart rate; HBP High blood pressure. P values relate to comparisons between Normal ABI and PAD ABI groups. For HBP, Smoking and Insulin, $P$ values are from the Chi-Square test.

Table 2. Physical Component Summary (PCS) and Mental Component Summary (MCS) scores from the health survey questionnaire and total score from the modified Baecke physical activity questionnaire, in diabetic patients with or without PAD.

\begin{tabular}{ccccc}
\hline & All & Normal $\mathrm{ABI}$ & PAD ABI & $P$ value \\
& $(\mathrm{N}=73)$ & $(\mathrm{N}=56)$ & $(\mathrm{N}=10)$ & 0.21 \\
PCS & $42.0 \pm 10.9$ & $42.9 \pm 11.2$ & $38.1 \pm 11.1$ & 0.26 \\
MCS & $48.9 \pm 13.2$ & $48.5 \pm 13.3$ & $53.4 \pm 11$ & 0.69 \\
\hline
\end{tabular}

$P$ values relate to comparisons between Normal ABI and PAD ABI groups. 
Table 3. Anthropometric and Body Composition variables for diabetic patients with or without PAD.

\begin{tabular}{|c|c|c|c|c|c|}
\hline & & 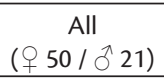 & 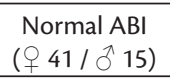 & $\begin{array}{l}\text { PAD ABI } \\
(96 / 03)\end{array}$ & $P$ value \\
\hline \multirow[t]{2}{*}{ TBW (kg) } & q & $29.09 \pm 3.87$ & $28.96 \pm 3.86$ & $30.32 \pm 4.92$ & 0.30 \\
\hline & $\delta$ & $36.99 \pm 4.53$ & $37.45 \pm 5.16$ & $34.57 \pm 1.96$ & 0.37 \\
\hline \multirow[t]{2}{*}{ FFM (Kg) } & q & $31.45 \pm 10.53$ & $39.27 \pm 5.15$ & $41.10 \pm 6.59$ & 0.30 \\
\hline & 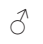 & $50.15 \pm 6.21$ & $50.80 \pm 7.06$ & $46.80 \pm 2.72$ & 0.41 \\
\hline \multirow[t]{2}{*}{$\mathrm{FM}(\mathrm{kg})$} & q & $37.60 \pm 7.21$ & $29.50 \pm 10.41$ & $30.87 \pm 11.97$ & 0.92 \\
\hline & $\delta$ & $21.11 \pm 11.09$ & $21.07 \pm 12.27$ & $25.50 \pm 2.42$ & 0.12 \\
\hline \multirow[t]{2}{*}{ PBF (\%) } & q & $41.60 \pm 6.84$ & $41.93 \pm 6.96$ & $41.88 \pm 7.23$ & 1.00 \\
\hline & $\delta$ & $28.33 \pm 8.09$ & $27.85 \pm 7.84$ & $35.23 \pm 1.85$ & 0.04 \\
\hline \multirow[t]{2}{*}{ SMM (Kg) } & q & $21.27 \pm 3.15$ & $21.17 \pm 3.11$ & $22.28 \pm 4.19$ & 0.31 \\
\hline & $\hat{\sigma}$ & $27.73 \pm 3.85$ & $28.17 \pm 4.40$ & $25.70 \pm 1.70$ & 0.41 \\
\hline \multirow[t]{2}{*}{ MBR (Kcal) } & q & $1255 \pm 142.1$ & $1242 \pm 147.4$ & $1310 \pm 100.8$ & 0.11 \\
\hline & $\hat{\sigma}$ & $1404 \pm 191.5$ & $1442 \pm 192.5$ & $1328 \pm 165.2$ & 0.34 \\
\hline \multirow[t]{2}{*}{$\mathrm{BMI}\left(\mathrm{Kg} / \mathrm{m}^{2}\right)$} & 우 & $29.85 \pm 5.73$ & $29.71 \pm 5.83$ & $31.45 \pm 6.59$ & 0.60 \\
\hline & $\delta$ & $26.27 \pm 4.40$ & $26.23 \pm 4.91$ & $28.40 \pm 2.31$ & 0.29 \\
\hline \multirow[t]{2}{*}{ BFMI $\left(\mathrm{Kg} / \mathrm{m}^{2}\right)$} & 운 & $12.83 \pm 4.51$ & $12.81 \pm 4.66$ & $13.50 \pm 4.91$ & 0.69 \\
\hline & 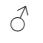 & $7.73 \pm 3.63$ & $7.62 \pm 3.91$ & $10.3 \pm 1.24$ & 0.07 \\
\hline \multirow[t]{2}{*}{ Waist (cm) } & 우 & $95.20 \pm 11.26$ & $95.20 \pm 11.43$ & $96 \pm 9.01$ & 0.83 \\
\hline & 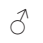 & $93.57 \pm 10.95$ & $92.73 \pm 12.06$ & $100.3 \pm 2.52$ & 0.09 \\
\hline \multirow[t]{2}{*}{$\mathrm{Hip}(\mathrm{cm})$} & q & $104.1 \pm 11.43$ & $104.1 \pm 11.88$ & $103.2 \pm 11.60$ & 0.65 \\
\hline & $\sigma^{2}$ & $99.52 \pm 7.41$ & $99.67 \pm 7.77$ & $105.0 \pm 3.61$ & 0.21 \\
\hline \multirow[t]{2}{*}{ WHR } & ㅇ & $0.91 \pm 0.08$ & $0.91 \pm 0.08$ & $0.91 \pm 0.08$ & 0.99 \\
\hline & $\widehat{0}$ & $0.93 \pm 0.06$ & $0.92 \pm 0.06$ & $0.95 \pm 0.01$ & 0.08 \\
\hline
\end{tabular}

TBW Total body water; FFM Fat free mass; FM Fat mass; PBF Percentage body fat; SMM Skeletal muscle mass; MBR Metabolic basal rate; BMI Body mass index; BFMI Body fat mass index; WHR Waist-to-hip ratio. P values relate to comparisons between Normal ABI and PAD ABI groups.

a)

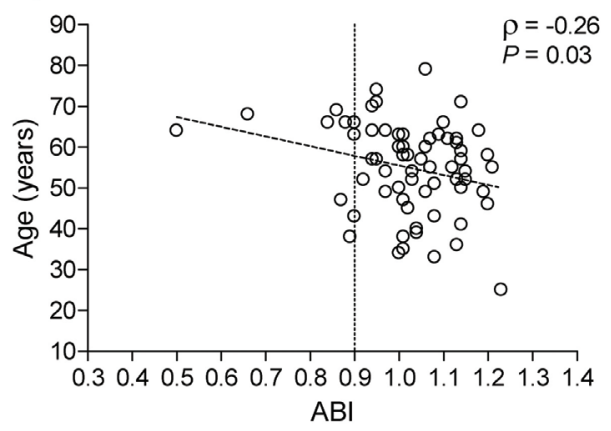

c)

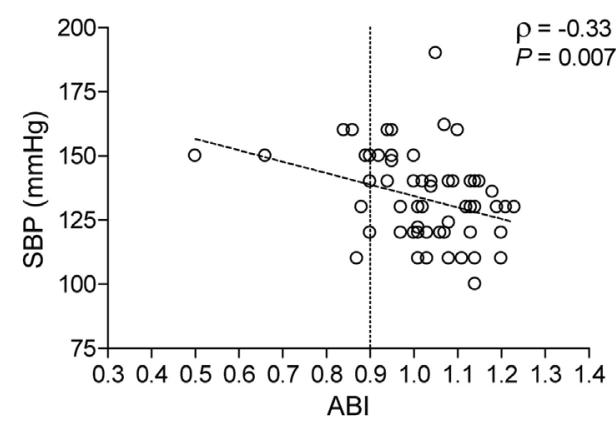

b)

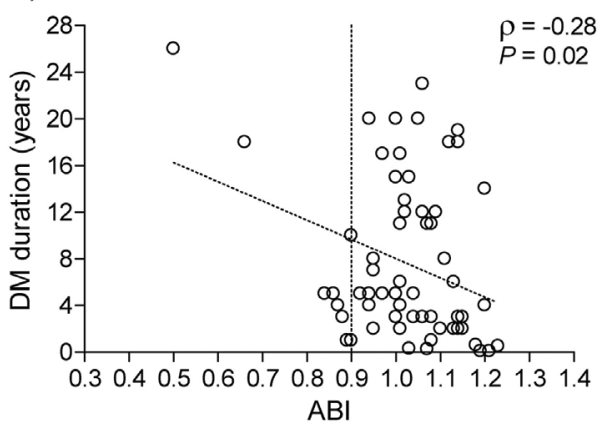

d)

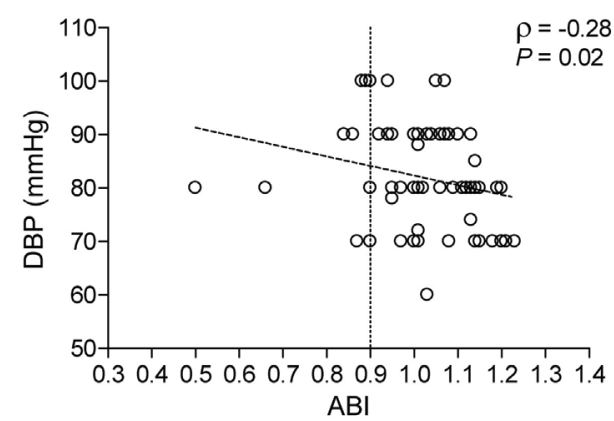

Figure 1. Correlations between $A B I$ and: age (a), diabetes duration (b), systolic blood pressure (SBP) (c) and diastolic blood pressure $(D B P)(d)$. The dotted line on the $A B I$ axis represents the cut-off point for normal $A B I$. The dotted line within the graph represents the linear regression curve. 
Table 4. Spearman coefficients for correlations between ABI and anthropometric and body composition variables, in diabetic patients broken down by sex.

\begin{tabular}{|c|c|c|c|c|c|c|c|c|c|c|c|c|}
\hline & & $\begin{array}{l}\text { TBW } \\
(\mathrm{Kg}) \\
\end{array}$ & $\begin{array}{l}\text { FFM } \\
(\mathrm{Kg})\end{array}$ & $\begin{array}{l}\mathrm{FM} \\
(\mathrm{Kg})\end{array}$ & $\begin{array}{l}\text { PBF } \\
(\%)\end{array}$ & $\begin{array}{c}\text { SMM } \\
(\mathrm{Kg})\end{array}$ & $\begin{array}{c}\text { MBR } \\
\text { (Kcal) }\end{array}$ & $\begin{array}{c}\mathrm{BMI} \\
\left(\mathrm{Kg} / \mathrm{m}^{2}\right)\end{array}$ & $\begin{array}{c}\text { BFMI } \\
\left(\mathrm{Kg} / \mathrm{m}^{2}\right)\end{array}$ & $\begin{array}{l}\text { Waist } \\
(\mathrm{cm})\end{array}$ & $\begin{array}{l}\text { Hip } \\
(\mathrm{cm})\end{array}$ & WHR \\
\hline \multicolumn{13}{|l|}{ MEN } \\
\hline \multirow[t]{2}{*}{$\mathrm{ABI}$} & $\rho$ & 0.36 & 0.36 & 0.22 & 0.05 & 0.35 & 0.28 & 0.17 & 0.11 & 0.05 & 0.18 & -0.16 \\
\hline & $P$ & 0.14 & 0.14 & 0.38 & 0.85 & 0.15 & 0.25 & 0.50 & 0.66 & 0.84 & 0.47 & 0.52 \\
\hline \multicolumn{13}{|c|}{ WOMEN } \\
\hline \multirow[t]{2}{*}{$A B I$} & $\rho$ & 0.27 & 0.28 & 0.14 & 0.05 & 0.28 & -0.05 & 0.13 & 0.05 & 0.22 & 0.16 & 0.12 \\
\hline & $P$ & 0.06 & 0.05 & 0.35 & 0.75 & 0.06 & 0.72 & 0.37 & 0.74 & 0.14 & 0.27 & 0.43 \\
\hline
\end{tabular}

TBW Total body water; FFM Fat free mass; FM Fat mass; PBF Percentage body fat; SMM Skeletal muscle mass; MBR Metabolic basal rate; BMI Body mass index; BFMI Body fat mass index; WHR Waist-to-hip ratio. Data correlations were determined by calculating Spearman correlation coefficients, represented by the Greek letter " $\rho$ ".

\section{DISCUSSION}

Very few studies have assessed the prevalence or impact of PAD in patients with diabetes in the Brazilian population. To our knowledge, this is the first study to assess the prevalence of PAD in T2DM patients with no prior diagnosis of PAD, treated by the public health system in Northeast Brazil. The prevalence of PAD in this population was $13.7 \%$. The ABI results were inversely correlated with age, diabetes duration and arterial blood pressure. The predominant disease classification was mild and, although the DM population had worse scores on the physical health summary of the general health questionnaire, at this degree of severity the presence of PAD had not yet been reflected in significant changes to quality of life, physical activity levels or body composition.

The prevalence of lower-extremity PAD in the general population has been determined in a series of epidemiological investigations that have used intermittent claudication or abnormal $\mathrm{ABI}$ as the criterion for diagnosis. ${ }^{1,2,4,5}$ Important epidemiological studies such as the Rotterdam study ${ }^{2}$ have found PAD prevalence rates of $19.1 \%$ in the elderly. The Edinburgh Artery Study ${ }^{1}$ described a similar prevalence for the general population above 55 years, but the observed prevalence of intermittent claudication was only $4.5 \%$. The prevalence of PAD in the general Brazilian population ${ }^{4}$ was $10.5 \%$ in a study of a total of 1159 participants distributed across all five of Brazil's geographical regions. In the Northeast of Brazil, which is the same geographical area in which the present study was conducted, prevalence was $14.9 \%$.

This study found a $13.9 \%$ prevalence of PAD among a sample of T2DM patients treated by the public health system at a University Hospital, slightly higher than the prevalence described for the general
Brazilian population. ${ }^{4}$ It is important to point out that although a validated claudication symptoms questionnaire was not administered, patients were asked specifically about claudication and responded that they did not suffer from claudication. Moreover, the population included in the study comprised a sample of volunteers who were free from complications secondary to DM and had no prior diagnoses of PAD (as defined in the inclusion criteria). The results of this study are consistent with the values reported in the Hoorn study, ${ }^{5}$ in which the range of PAD prevalence was approximately $15-20 \%$ in patients defined as diabetics according to the criteria adopted for the study. ${ }^{2}$

As has been demonstrated in previous studies ${ }^{2,4,25,26}$ and confirmed in the present study, advancing age was correlated with increased prevalence of PAD. Significant correlations were observed between ABI and age, $\mathrm{ABI}$ and patient-reported diabetes duration, and between $\mathrm{ABI}$ and arterial blood pressure, in line with previous findings reported by $\mathrm{Yu}$ et al. ${ }^{27}$

In the present study, patients with diabetes had lower scores on the physical component summary of the general health questionnaire, when compared to the standardized general population score. Nevertheless, the presence of PAD did not significantly alter the values of either the physical or mental health summaries. Similarly, there was no correlation between ABI and PCS or MCS. A likely explanation is related to the fact that the volunteers in this study had mild PAD (with the majority of abnormal ABI values falling within the range from 0.8 to 0.9$)^{21,28}$ and were asymptomatic for intermittent claudication, with the result that at this stage they had no functional limitations resulting from the disease that could directly interfere with quality of life. Long et al. ${ }^{14}$ also evaluated quality of life in patients with symptomatic and non-symptomatic PAD, finding a very similar value for the correlation 
between PCS and ABI $(r=0.25)$ to the figure reported here. These authors concluded that it is the severity of symptoms rather than $\mathrm{ABI}$ itself that is determinant of lower scores on the health-related quality of life questionnaire.

Physical activity as assessed by the modified Baecke questionnaire was not different between patients with normal ABI and PAD ABI. There was no significant correlation between the ABI values and the Baecke questionnaire total scores. It is possible that changes in physical activity level are not greatly impaired in T2DM patients with mildly reduced $\mathrm{ABI}$. It is also possible that the questionnaire does not offer the necessary specificity to enable detection of changes in the physical activity levels of T2DM patients caused by mild to moderate PAD. However, it should be noted that the T2DM population studied here had mean values for the questionnaire domains that were consistent with low levels of physical activity, according to findings published by Hertogh et al., ${ }^{29}$ who compared Baecke questionnaire scores with results for total expended energy, measured using the doubly labeled water method.

Assessment of the body composition of the population enrolled on this study showed that values for FM, PBF and BFMI were all above the normal levels, as predicted for the general population (Caucasians) by Kyle et al., ${ }^{30}$ who also used the bioelectrical impedance method. Notwithstanding, in both sexes there was no identifiable impact from PAD on the values of the body composition variables studied, with the exception of BFP in men. It should be borne in mind that the low number of subjects restricts the statistical power available for comparison between groups, especially for men in the PAD ABI group. This study limitation is the result of employing a convenience sample and the fact that patients were not selected based on diagnosis of PAD, but were randomly identified in a population of T2DM patients.

Overall, the majority of women in the present study had PBF results above the cut-off values. For example, $95.8 \%$ of women in the age group ranging from 40 to 59 years old were above predicted normal values. ${ }^{30}$ The same is true for men in that age group (77.8\% are above cut-off values). Moreover, there was a predominance of central fat (indicated by WHR and segmental impedance) in this population, especially among the women, which increases their cardiovascular risk. ${ }^{18}$ There was a strong trend towards correlations between fat-free mass $(P=0.05)$ and skeletal muscle mass $(P=0.06)$ and $\mathrm{ABI}$ values in women, but a more comprehensive study of T2DM patients with lower ABI levels, or perhaps with symptomatic PAD, will be needed to clarify whether PAD could have a negative impact on body composition variables.

The present study suffers from a limitation in terms of sample size, making it difficult to extrapolate the prevalence found in this T2DM sample to a larger population, such as the national Brazilian population, but it nevertheless provides new and important data for raising awareness of PAD in DM. The ABI method is widely accepted and recommended for PAD diagnosis, $, 21,22$ especially in epidemiological studies, but it must be acknowledged that there is a possibility that it may be insufficient to enable full diagnosis in DM patients, in view of the high frequency of abnormal $\mathrm{ABI}$ values found, as the present study has shown.

In summary, this study demonstrated that PAD newly identified in T2DM patients, which was predominantly of mild severity and asymptomatic, was not associated with reduced physical function or impaired quality of life, as assessed by validated questionnaires. This implies that T2DM patients who do not perceive physical limitations may not have their PAD identified, thereby missing the chance to prevent major complications, unless clinical assessment of ABI is performed as recommended. . $^{3,22}$ Therefore, this study underscores the importance of routine screening of patients with diabetes for PAD, using ABI, because the absence of symptoms or of functional limitations perceived by the patient may hinder clinical diagnosis.

\section{CONCLUSIONS}

This study found a $13.7 \%$ prevalence of PAD, diagnosed with the ankle-brachial index, in a sample of Brazilian T2DM patients with no prior diagnosis of PAD, treated by the public health system. Among these patients, who predominantly had asymptomatic mild PAD, the condition was not yet associated with further impairment of quality of life, physical activity levels or body composition.

\section{ACKNOWLEDGMENTS}

This study received financial support from the PPSUS III-DECIT/SCTIE/MS grant, awarded by the National Research Council (CNPq), FAPERN and SESAP/RN. We would also like to thank Meriely $\mathrm{S}$. Fonseca for her assistance with data collection. 


\section{REFERENCES}

1. Fowkes FG, Housley E, Cawood EH, Macintyre CC, Ruckley CV, Prescott RJ. Edinburgh Artery Study: prevalence of asymptomatic and symptomatic peripheral arterial disease in the general population. Int J Epidemiol. 1991;20(2):384-92. http://dx.doi. org/10.1093/ije/20.2.384. PMid:1917239

2. Meijer WT, Hoes AW, Rutgers D, Bots ML, Hofman A, Grobbee DE. Peripheral arterial disease in the elderly: The Rotterdam Study. Arterioscler Thromb Vasc Biol. 1998;18(2):185-92. http://dx.doi. org/10.1161/01.ATV.18.2.185. PMid:9484982

3. Norgren L, Hiatt WR, DormandyJA, Nehler MR, Harris KA, Fowkes FG. Inter-society consensus for the management of peripheral arterial disease (TASC II). J Vasc Surg. 2007;45(1):S5-S67. http:// dx.doi.org/10.1016/j.jvs.2006.12.037

4. Makdisse M, Pereira AC, Brasil DP, et al, Prevalence and risk factors associated with peripheral arterial disease in the Hearts of Brazil Project. Arq Bras Cardiol. 2008;91(6):370-82. PMid:19142364.

5. Beks PJ, Mackaay AJ, Neeling JN, Vries H, Bouter LM, Heine RJ. Peripheral arterial disease in relation to glycaemic level in an elderly Caucasian population: the Hoorn study. Diabetologia. 1995;38(1):86-96. http://dx.doi.org/10.1007/BF02369357. PMid:7744233

6. Marso SP, Hiatt WR. Peripheral arterial disease in patients with diabetes. J Am Coll Cardiol. 2006;47(5):921-9. http://dx.doi. org/10.1016/j.jacc.2005.09.065. PMid:16516072

7. Meves SH, Diehm C, Berger K, et al, Peripheral arterial disease as an independent predictor for excess stroke morbidity and mortality in primary-care patients: 5 -year results of the get $A B \mid$ study. Cerebrovasc Dis. 2010;29(6):546-54. http://dx.doi. org/10.1159/000306640. PMid:20375496

8. Luo Y, Li X, Li J, et al. Peripheral arterial disease, chronic kidney disease, and mortality: the Chinese Ankle Brachial Index Cohort Study. Vasc Med. 2010;15(2):107-12. http://dx.doi. org/10.1177/1358863X09357230. PMid:20133341

9. Criqui $M H$, Ninomiya JK, Wingard DL, Ji M, Fronek A. Progression of peripheral arterial disease predicts cardiovascular disease morbidity and mortality. J Am Coll Cardiol. 2008;52(21):1736-42. http://dx.doi.org/10.1016/j.jacc.2008.07.060. PMid:19007695

10. American Diabetes Association. Peripheral arterial disease in people with diabetes. Diabetes Care. 2003;26(12):3333-41. http:// dx.doi.org/10.2337/diacare.26.12.3333. PMid:14633825

11. Jude EB, Oyibo SO, Chalmers N, Boulton AJ. Peripheral arterial disease in diabetic and nondiabetic patients: a comparison of severity and outcome. Diabetes Care. 2001;24(8):1433-7. http:// dx.doi.org/10.2337/diacare.24.8.1433. PMid:11473082

12. Breek JC, Hamming JF, De Vries J, van Berge Henegouwen DP, van Heck GL. The impact of walking impairment, cardiovascular risk factors, and comorbidity on quality of life in patients with intermittent claudication. J Vasc Surg. 2002;36(1):94-9. http:// dx.doi.org/10.1067/mva.2002.124369. PMid:12096264

13. Oka RK, Sanders MG. The impact of type 2 diabetes and peripheral arterial disease on quality of life. J Vasc Nurs. 2005;23(2):61-6, quiz 67-8. http://dx.doi.org/10.1016/j.jvn.2005.03.032. PMid:16102474

14. Long J, Modrall JG, Parker BJ, Swann A, Welborn MB 3rd, Anthony T. Correlation between ankle-brachial index, symptoms, and health-related quality of life in patients with peripheral vascular disease. J Vasc Surg. 2004;39(4):723-7. http://dx.doi.org/10.1016/j. jvs.2003.12.006. PMid:15071432

15. Izquierdo-Porrera AM, Gardner AW, Bradham DD, et al. Relationship between objective measures of peripheral arterial disease severity to self-reported quality of life in older adults with intermittent claudication. J Vasc Surg. 2005;41(4):625-30. http:// dx.doi.org/10.1016/j.jvs.2005.01.012. PMid:15874926

16. Lwanga SK, Lemeshow S, World Health Organization. Sample size determination in health studies: a practical manual. Geneva: World Health Organization; 1991. http://www.who.int/iris/ handle/10665/40062\#sthash.HRjLd7bW.dpuf

17. World Health Organization. Obesity: preventing and managing the global epidemic. Report of a WHO consultation. World Health Organ Tech Rep Ser. 2000;894:i-xii, 1-253. PMid:11234459.

18. World Health Organization. Waist circumference and waisthip ratio: report of a WHO expert consultation. Geneva: WHO Document Production Services; 2008.

19. Malavolti M, Mussi C, Poli M, et al. Cross-calibration of eightpolar bioelectrical impedance analysis versus dual-energy $\mathrm{X}$-ray absorptiometry for the assessment of total and appendicular body composition in healthy subjects aged 21-82 years. Ann Hum Biol. 2003;30(4):380-91. http://dx.doi.org/10.1080/030144603100 0095211. PMid:12881138

20. Demura S, Sato S, Kitabayashi T. Percentage of total body fat as estimated by three automatic bioelectrical impedance analyzers. J Physiol Anthropol Appl Human Sci. 2004;23(3):93-9. http://dx.doi. org/10.2114/jpa.23.93. PMid:15187381

21. Hirsch AT, Haskal ZJ, Hertzer NR, et al, ACC/AHA 2005 Practice Guidelines for the management of patients with peripheral arterial disease (lower extremity, renal, mesenteric, and abdominal aortic): a collaborative report from the American Association for Vascular Surgery/Society for Vascular Surgery, Society for Cardiovascular Angiography and Interventions, Society for Vascular Medicine and Biology, Society of Interventional Radiology, and the ACC/AHA Task Force on Practice Guidelines (Writing Committee to Develop Guidelines for the Management of Patients With Peripheral Arterial Disease): endorsed by the American Association of Cardiovascular and Pulmonary Rehabilitation; National Heart, Lung, and Blood Institute; Society for Vascular Nursing; TransAtlantic Inter-Society Consensus; and Vascular Disease Foundation. Circulation. 2006;113(11):e463654. http://dx.doi.org/10.1161/CIRCULATIONAHA.106.174526. PMid:16549646

22. Rooke TW, Hirsch AT, Misra S, et al, 2011 ACCF/AHA focused update of the guideline for the management of patients with peripheral artery disease (updating the 2005 guideline): a report of the American College of Cardiology Foundation/American Heart Association Task Force on Practice Guidelines: developed in collaboration with the Society for Cardiovascular Angiography and Interventions, Society of Interventional Radiology, Society for Vascular Medicine, and Society for Vascular Surgery. J Vasc Surg. 2011;54(5):e32-58. http://dx.doi.org/10.1016/j.jvs.2011.09.001. PMid:21958560

23. Ciconelli RM, Ferraz MB, Santos W, Meinão I, Quaresma MR. Brazilian-Portuguese version of the SF-36. A reliable and valid quality of life outcome measure. Rev Bras Reumatol. 1999;39:143-50.

24. Florindo AA, Latorre MRDO. Validação e reprodutibilidade do questionário de Baecke de avaliação da atividade física habitual em homens adultos. Rev Bras Med Esporte. 2003;9:121-8.

25. Criqui $M H$, Langer RD, Fronek A, et al. Mortality over a period of 10 years in patients with peripheral arterial disease. N Engl J Med. 1992;326(6):381-6. http://dx.doi.org/10.1056/ NEJM199202063260605. PMid:1729621

26. Escobar C, Blanes I, Ruiz A, et al. Prevalence and clinical profile and management of peripheral arterial disease in elderly patients with diabetes. Eur J Intern Med. 2011;22(3):275-81. http://dx.doi. org/10.1016/j.ejim.2011.02.001. PMid:21570647 
27. Yu JH, Hwang JY, Shin MS, et al. The prevalence of peripheral arterial disease in korean patients with type 2 diabetes mellitus attending a university hospital. Diabetes Metab J. 2011;35(5):54350. http://dx.doi.org/10.4093/dmj.2011.35.5.543. PMid:22111047

28. Arain FA, Cooper LT Jr. Peripheral arterial disease: diagnosis and management. Mayo Clin Proc. 2008;83(8):944-9; quiz 949-50. http://dx.doi.org/10.1016/S0025-6196(11)60771-4. PMid:18674479

29. Hertogh EM, Monninkhof EM, Schouten EG, Peeters PH, Schuit A). Validity of the modified Baecke questionnaire: comparison with energy expenditure according to the doubly labeled water method. Int J Behav Nutr Phys Act. 2008;5:30. http://dx.doi. org/10.1186/1479-5868-5-30. PMid:18505554

30. Kyle UG, Schutz Y, Dupertuis YM, Pichard C. Body composition interpretation. Contributions of the fat-free mass index and the body fat mass index. Nutrition. 2003;19(7-8):597-604. http:// dx.doi.org/10.1016/S0899-9007(03)00061-3. PMid:12831945
Correspondence

Fernando Augusto Lavezzo Dias

Universidade Federal do Paraná, Centro Politécnico, Departamento de Fisiologia, Setor de Ciências Biológicas Cel. Francisco H. dos Santos, s/n - Jd. das Américas CEP 81531-980 - Curitiba (PR), Brazil Tel.: +55 (41) 3361-1644 E-mail:faldias@ufpr.br

Author information ATNS - BSC and MSc in Physical Therapy from Universidade Federal do Rio Grande do Norte (UFRN). PhD candidate in Physical Therapy

GAFF - BSc in Physical Therapy from Universidade Estadual de Londrina (UEL) and PhD in Neuroscience from Universidade Autonoma de Barcelona/Hospital de la Santa Creu i Sant Pau AGCBS - BSc in Physical Therapy from UFRN. MSc candidate in Physical Therapy (UFRN)

CTDR - BSc in Physical Therapy from Pontificia Universidade Católica do Paraná and MSc in Physical Therapy (UFRN)

METDJr - BSc in Medicine from UFRN and MSc in Biochemistry from UFRN

AGPS - BSC in Medicine from UFRN and in Cardiology from Universidade de São Paulo (USP)

FALD - BSC in Physical Therapy from UEL and PhD in Molecular and Cellular Biology/Physiology from Universidade Federal do Paraná

Author contributions Conception and design: FALD, GAFF Analysis and interpretation: ATNS, GAFF, AGCBS, CTDR, MEDJr, AGPS

Data collection: ATNS, CTDR, AGCBS Writing the article: ATNS, FALD, CTDR, AGCBS Critical revision of the article: GAFF, METDJr, AGPS, FALD Final approval of the article*: ATNS, GAFF, AGCBS, CTDR, METDJr, AGPS, FALD

Statistical analysis: FALD, ATNS Overall responsibility: FALD, ATNS

Obtained funding: FALD

*All authors have read and approved of the final version of the article submitted to I Vasc Bras. 